\title{
Assessment of Turnover Intention and Associated Factors Among Health Information Technology Professionals Working in Public Health Institution, South Gondar Zone, Northwest Ethiopia
}

Libsuye Yalgaw Zimamu ( $\sim$ libsuye@gmail.com )

DebreTabor Health Science College

Gashaw Mehiret Wubet

Debre Tabor University

\section{Research Article}

Keywords: intention to leave, health information technology professionals, public health institution, Ethiopia

Posted Date: December 13th, 2021

DOI: https://doi.org/10.21203/rs.3.rs-1166672/v1

License: (c) (i) This work is licensed under a Creative Commons Attribution 4.0 International License.

Read Full License 
ASSESSMENT OF TURNOVER INTENTION AND ASSOCIATED FACTORS AMONG HEALTH INFORMATION TECHNOLOGY PROFESSIONALS WORKING IN PUBLIC HEALTH INSTITUTION, SOUTH GONDAR ZONE, NORTHWEST ETHIOPIA

Libsuye Yalgaw Zimamu (BSc)*1

${ }^{1}$ Department of Health Informatics, Debretabor Health Science College, Debretabor, Ethiopia;

Gashaw Mehiret Wubet (MD)*2

${ }^{2}$ School of Medicine, College of Medicine and Health Sciences, Debre Tabor University, Debre Tabor, Ethiopia

*Corresponding author: Libsuye Yalgaw Zimamu (BSc)* ${ }^{1}$ Department of Health Informatics, Debretabor Health Science College, Debretabor, Ethiopia;

Email libsuye@gmail.com

Phone +251932859975 


\begin{abstract}
Background: Place of work turnover is critical to health information technology professionals (HIT) and health information systems as it indications dropping skilled and competent health information professionals. However, the progress of surviving plans requests a strong acceptance of the place of work variables that either inspire health information staff to persist active or principal them to dispensation their recent working organization.
\end{abstract}

Objective: This study was deliberate to measure intention to leave and associated factors among health information technology professionals working in south Gondar zone public health institution, Amhara Region, Ethiopia

Methods: A cross-sectional study was carried out among 122 health information technology professionals. Data were collected using structured pre-tested self-administered questionnaires from September 1 to October 1/2020. The collected data were entered into Epi-info Version 7 and exported to SPSS version 20 software for analysis. Bivariate and multivariable logistic regression was employed to detect influences associated with dependent and independent variables. Odds ratio (OR), with $95 \% \mathrm{CI}$ and $\mathrm{p}<0.05$ were computed to determine the level of significance.

Results: Based on the operational definition the total score of intent to leave health information technology professionals from the organization was 64.8\% [95\% CI: 56.6-72.9]. Among the applicant variables for multivariable analysis 3 variables like the marital status of the respondents [OR: 0.49(0.231-1.042)p: value 0.000], performance appraisal of the respondents [OR: 7.0(2.6618.45) p: value 0.000] and recognition of the respondents [OR: .447(.783-3.513) p: value 0.002] had to have a significant association with intention to leave and performance appraisal of the respondents were significantly associated 8.29 times [AOR: 8.29(3.002-22.889)p: value 0.001] to leave of the respondents from the working organization.

Conclusion and recommendation: The magnitude of health information professionals' intention to leave was found to be high, which can extremely affect the coverage and quality of information management and use of information for decisions in the zone. Health care policy-makers and hospital managers need to develop and institutionalize evidence-based retention strategies taking into consideration the predictors of health information professionals' intention to leave. 
Keywords: intention to leave, health information technology professionals, public health institution, Ethiopia.

\section{Background}

Health information technology (HIT) is discipline practical to health and health care. It maintenances health information management systems through electronic systems and the safe exchange of health information between clients, workers, financiers, and quality monitors [1]. Health IT (health information technology) is the part of IT including the plan, development, creation, use, and maintenance of information systems for the health sector, Automated and interoperable healthcare information systems will continue to improve medical care and public health, lower costs, increase efficiency, reduce errors and improve patient satisfaction, while also optimizing reimbursement for ambulatory and inpatient healthcare providers $[1,2]$.

Regardless of the types of organizations, human resources are important organizational assets in determining core organizational capability, effectiveness, and performance, together with other sorts of resources such as material or intellectual resources [4].

Employee turnover refers to the process of employees leaving an organization and having to be replaced. It is a problem that affects all organizations and has become a focus of healthcare organizations because of high replacement costs $[5,6]$.

\section{Methods}

\section{Study area and periods}

The study was conducted under the south Gondarzonal health department Public health institution (SGZHD), Ethiopia. The study was conducted from March to April /2020.

\section{Study Design}

A cross-sectional study design was conducted.

\section{Population}

\section{Source population}

All health information technology professionals working in south Gondar zone public health institutions were taken as source population.

\section{Study population}

The study subjects were all health information technology professionals working in public health institutions for six (6) months and above during the study period. 


\section{Inclusion and Exclusion Criteria}

\section{Inclusion Criteria}

$>$ Full-time employees who were working in public health institutions of south Gondar zonal health department.

\section{Exclusion Criteria}

$>$ Health information technology professionals who were less than 6 months' work experience.

\section{Sample Size Determination and Sampling Technique}

The sample size of the study was the total population of health information technology (HIT) who was working in a public health facility under the south Gondar zone health department and the sampling technique was a total survey.

\section{Data collection, Quality control, and Analysis}

\section{Data Collection Tools}

An English version self-administered questionnaire was adapted from different works of literature were used to collect data on socio-demographic characteristics, job satisfaction, and their intention to leave the organization.

Job satisfaction was measured with a forty-seven-item scale that included twelve subscales adapted and customized into the local context from previous studies [32, 34] compensation and benefit, professional opportunities, work environment, supervisor support, relationship and coworker, organizational policy, and strategy, performance appraisal, nature of work, recognition, workload, and autonomy. These items were answered on a five-point Likert scale with response options ranging from 1 (very dissatisfied) to 5 (very satisfied) [35].

The dependent variable, intention to leave the organization was measured by three items. [36]. The respondents were asked to indicate the extent of their agreement using a five-point scale ( $1=$ strongly disagree, $5=$ strongly agree). The total score was obtained by calculating the sum of all items on the scale.

\section{Data collection procedure}

Data were collected through a structured self-administered questionnaire by the health information technology (HIT's) from each Woreda health office under the Zonal health department. The principal investigator was distributed and provided a one-hour orientation about the purpose and processes of data collection for a single health information technology (HIT's) of data collector in each health facility. Then the principal investigator were collect completed 
questionnaires from each participant government health facility found in the south Gondar Zonal health department during the study period.

\section{Study Variables}

Dependent Variable

$\checkmark$ Turnover intention

Independent Variables

A. Socio-demographic and economic factors

$\checkmark$ Age

$\checkmark$ Sex

$\checkmark$ Marital status

$\checkmark$ Work experience

$\checkmark$ Working institutions

$\checkmark$ Educational level

$\checkmark$ Job position

$\checkmark$ Salary

$\checkmark$ Family arrangement

B. Job Satisfaction

$\checkmark$ Reward and Benefit

$\checkmark$ Professional development opportunity

$\checkmark$ Autonomy

$\checkmark$ Organizational policy and strategy

$\checkmark$ Performance appraisal

$\checkmark$ Work environment

$\checkmark$ Co-worker relationship

$\checkmark$ Supervisor support

$\checkmark$ Workload

$\checkmark$ Nature of work 


\section{Operational definitions}

Health Information Technician (also known as health information technology Professionals): Anyone who has earned a Diploma and/or bachelor's degree or higher in health information technology from an accredited college or university.

Turnover intention: the intention of an employee to leave their organization in the new future. Respondents who will be scored more than $60 \%$ of the sum of all the intention to leave scale items will be considered as showing the Intention to leave [37].

Job satisfaction level item score: All items are scored on 5 point liker scale as 1, 2, 3,4 , and 5 to score respondents ${ }^{\text {ee }}$ satisfaction level on the respective item as very satisfied, satisfied, neutral, dissatisfied, and very dissatisfied respectively.

Work Environment: describes the quality of the working environment both its physical qualities and the degree to which it provides meaningful work. Supervisor support: describes the supervisors' responsibility both in preventing and solving employee problems.

Co-worker Relationship: Describes the participants' interpersonal relationships within their workplace.

Compensation and benefit describe Employees' expectations of fairness and adequate compensation on a day's pay for a day's work.

Promotion: describes the availability of advancement opportunities for employees within the organization.

Autonomy: reflects participants' autonomy in initiating and continuing their work behaviors and processes such as making decisions about work methods, pace, and effort.

Performance appraisal: describes the participants feeling on the measurement of their actual performance.

Nature of work: describes the type of work the participants do (its Variety, meaningfulness...).

Workload: describes the participant's work requirement, the amount of time, and resources for this requirement. 


\section{Data processing and analysis procedures}

The collected data were checked for completeness. Then, it was coded, organized, and entered into Epi-info Version 7 and exported to SPSS version 20 software for cleaning, merging, and analysis. Tables and graphs were used to present the result. Descriptive statistical analyses such as frequencies and percentages were used to describe the study population characteristics and responses to the questionnaire items. Mean \& standard deviation was also computed to explore the dominant turnover intention and satisfaction status of health information technology employees. Binary logistic regression was conducted to identify the factors that associate with the dependent variable (turnover) with a 0.05 Significance level. The model fitness was checked by Homier and Lemeshow test, based on the findings of Homier and Lemeshow test the model was fitted at $69.1 \%$ and the chi-square was used to test the association between the dependent and independent variables and there was shown a significant association between dependents and independent variables with p-value $<0.046$.

\section{Data quality management}

To assure the quality of data pre-test was conducted on $10 \%$ of the total sample size (13) in Bahirdar Town Health Institutions. Based on the pre-test, the tools were assessed for clarity; understanding ability, flow, and structure. Additionally, all completed questionnaires were collected and examined by the investigator. Twelve data collectors (diploma HIT) and two supervisors (BSc HIT) were assigned for data collection and training was given for one day. Before the data collection, the questionnaire was translated to Amharic and then back to English after data collection to ensure its consistency.

\section{Ethical consideration}

Ethical clearance was obtained from the ethical committee of the institute of public health, college of medicine and health science, Debrtabor University. Before communicating the study participants' Official letters were given from Debrtabor University (DTU) and the selected health facilities to get a supportive letter. Then permission from specific hospital management and other relevant managerial hierarchy to conduct the study was obtained. The name was not to be written on the 
questionnaire and the confidentiality of the data was been kept at all levels of the study.

\section{Results}

\section{Socio-demographic characteristics of the respondents}

Of the total 128 study subjects, 122(95.3\%) were involved in this study and it produces a response rate of $95.3 \%$. The median age (IQR) of the study participants was 27 (23-36) years. The majority of respondents, 73(59.8\%) were females, and more than half of the respondents, $65(53.63 \%)$ were single and the majority of the respondents, 112 (91.8\%) had a diploma in health information technology. The majority of the respondents, 90(73.8\%) were working in the health center and the mean monthly salary of the respondents was 3925 Ethiopian birr (Table1).

\section{Factors affect turnover intention to Health Information Professionals}

\section{Job Satisfaction}

Based on the operational definition the overall score of intention to leave of health information technology professionals from the organization was $64.8 \%$ [95\% CI: 56.6-72.9]. The findings of intention to leave were consistent with the operational definition. The findings of levels of job satisfaction showed that health information technology professionals expressed a high level of satisfaction with co-worker relationship 114 (93.4\%), organizational Policy and strategy 90(73.8\%), Supervisor support 84(68.9\%). On the other hand, pay and benefit 118 (96.7\%), Respondents having alternative job opportunities 120(98.4\%), educational development 103(84.4 $\%)$, Workload $82(67.2 \%)$, and Performance appraisal 74(60.7\%) were reported as unsatisfied (Table2).

\section{Factors associated with intention to leave}

Findings based on the analytical part, which results, variables such as sex of the respondents [OR: 1.74(0.82-3.7)],marital status of the respondents [OR:0.49(0.2311.042)], current position of the respondents[OR:0.421(0.073-1.042)] and[OR:0.32(.099-1.005)] ,monthly salary of the respondents [OR: 3.7(.561-24.42)] and[OR: 2.4(.374-15.38)],family arrangement of the respondents[OR: .53(.248 1.143)],performance appraisal of the respondents [OR: 7.0(2.66-18.45)],autonomy of the respondents [OR:1.82(.845-3.918)], co-worker relationship of the Assessment of turnover intention and associated factors among health information technology (HIT) professionals 
respondents[OR:.245(.029-2.060)], recognition of the respondents [OR: .447(.7833.513)], and nature of the work[OR: 1.659(.206-.972)] were having a p-value less than 0.2 , but variables such as sex, the current position of the respondents, the monthly salary of the respondents and autonomy of the respondents were disappeared from the final stage of multivariable analysis. Among the candidate variables for multivariable analysis 3 variables like the marital status of the respondents [OR: 0.49(0.231-1.042)], performance appraisal of the respondents [OR: 7.0(2.66-18.45)] and recognition of the respondents [OR: .447(.783-3.513)] had to have a significant association with intention to leave, but all the above variables with a p-value of less than 0.2 are exported to multivariable conditional forward analysis. From the above result scenario, performance appraisal of the respondents was significantly associated 8.29 times [OR: 8.29(3.002-22.889)] to leave of the respondents from the working organization compared with those who had no performance appraisal but participants who were engaged with marriage had $40.35 \%$ preventive factors for intention to leaves when compared with singles [OR:0. 40349(.172-.948)].Similarly being recognized by the organization had $42.1 \%$ times reduce the risk of intention to leave as compared with not recognized respondents [OR: .421(.178-.992)],(table 3).

\section{Discussion}

The current study tried to assess the magnitude of intention to leave among health information technology professionals and the overall score of intention to leave of health information technology professionals from the organization in the study area was $64.8 \%$ [95\% CI: 56.6-72.9]. Besides intention to leave off those health information technology professionals majority of professionals had a high level of satisfaction with co-worker relationship 114 (93.4\%), organizational Policy and strategy 90(73.8\%), Supervisor support 84(68.9\%). On the other hand, pay and benefit 118 (96.7\%), educational development 103(84.4\%), Workload 82 (67.2\%), and Performance appraisal 74(60.7\%) were reported as unsatisfied. Factors like performance appraisal of the respondents were significantly associated 8.29 times to leave of the respondents from the working organization compared with those who had no any performance appraisal but participants who were engaged with marriage had $40.35 \%$ preventive factors for intention to leave when compared with singles and being recognized by the organization had $42.1 \%$ times reduce the risk of intention to live as compared with not recognized respondents.

The total magnitude of health information technology professionals for the intention to leave their organization was $64.8 \%$ [95\% CI: 56.6-72.9]. a concurrent and similar Assessment of turnover intention and associated factors among health information technology (HIT) professionals 
study conducted in Ethiopia in the university of Gondar referral hospital and Gambella region revealed that $52.5 \%$ and $48.4 \%$ of the health professionals had shown an intention to leave their current work within one year respectively, The two studies showed that intention to leave of health professionals among Gondar referral hospital and Gambella region found to be lower than the current study, this may be in the current study area absence of different enforcements to retain those health information technology professionals, lack of motives, bad working environment and the tendency of professionals to leave from this environment and shift their working areas to another environment from the region[19, 20]. As shown above, the current study revealed that the overall magnitude of intention to leave among health information technology professionals had been $64.8 \%$. A similar study was done in Southwest Ethiopian, Jimma zone health institutions intention to reveal that $59.4 \%$ of the health professionals had intended to leave. The study findings from the Jimma zone and the findings of the current study are in line with each other. The possibility of similarity among the two studies may be due to similarity in payment and other benefits, the similarity in professional development, similarities in family arrangements, and similarities in recognition and rewards [17].

Similar studies in developed countries also showed that no different from studies in Ethiopia such as studies in Jimma, Gambella, and Gondar University. For instance, the study conducted by Iraqi doctors on the magnitude of intention to leave their organization revealed that $55.2 \%$ were actively seeking alternative employment jobs due to intention to leave. The study findings of the current research are higher by intention to leave as compared with the study conducted in Iraqi. The higher intention to leave among the current study participants may be due to a good working environment, scarcity of extra benefits other than salary, conflicts with managers, and dissimilarities among study areas, which means differences in economic status among the two comparing study areas [15].

From the current study majority of the study participant, (93.4\%) were satisfied with the co-worker relationship, and (73.8\%) of participants were satisfied with organizational Policy and strategy but were dissatisfied with pay and benefit 118 (96.7\%), and educational development 103(84.4\%). A similar study conducted in the Gambella region showed that intention to leave was higher for those who were dissatisfied with their salary $(78.8 \%)$, educational opportunity $(76.0 \%)$, and working environment $(76.3 \%)[20]$. The current study revealed that higher numbers of health 
information technology professionals were dissatisfied than the above study. The possibility of dissatisfaction would be due to lack of professional development, poor payments and benefits, lack of a comfortable working environment, and lack of motivation and incentives for those who perform better [20].

From this study, about $84.4 \%$ of study participants were dissatisfied with lack of educational development, similarly a study conducted in Sub-Saharan Africa showed that about $28 \%$ of study subjects were dissatisfied with lack of professional development and the major reason for leaving the previous job. Higher numbers of the study participants were dissatisfied with the current study than the above study with lack of educational development. The possible reason for dissatisfaction was a lack of opportunity for professional development [27].

Factors like performance appraisal of the respondents were significantly associated 8.29 times to leave but the marriage had $40.35 \%$ and is recognized by the organization had $42.1 \%$ times reduce the risk of intention to live respectively. A similar study conducted in Bahirdar showed health professionals never married and married 27.58 and 11.45 times more likely to leave the public health sector as compared to Divorced Marital status. The findings of the current study are inversely related to the above study that means marriage is a preventive factor for intention to leave for the current study but a risk factor for the above study. The possible difference may be due to married and stay the two couples in similar residencies from the current study [31]. Generally, the magnitude of intention to leave from the current study is higher and influenced by factors like performance appraisal.

\section{Conclusions}

The magnitude of health information professional's intention to leave was found to be high, which can extremely affect the coverage and quality of information management and use of information for decisions in the zone.

\section{Competing interests}

The authors report no conflicts of interest

Funding: This research didn't receive any grants from any funding agency in the public, commercial, or not-for-profit sectors. 


\section{Authors' contributions}

LibsuyeYalgawZimamu,and Gashaw Megiret Principal Investigator and data analysis respactivelly.

\section{Acknowledgments}

First I would like to express our gratitude to Debrtabor university, the school of medicine, and health science for providing this opportunity to develop a thesis report and allowing me to undertake my area of interest.

\section{References}

[1] Tilahun, B., et al. New bachelor's degree program in HEALTH INFORMATION TECHNOLOGY in Ethiopia: curriculum content and development approaches. in MIE. 2014.

[2] Rose, A.F., et al., Using qualitative studies to improve the usability of an EMR. Journal of biomedical informatics, 2005. 38(1): p. 51-60.

[3] Masic, I., The History and New Trends of Medical Informatics. Donald School Journal of Ultrasound in Obstetrics and Gynecology, 2013. 7: p. 72-83.

[4] Xiao, X.-Y., W. Chen, and H.-G. Yang, Multi-uncertainty assessment for failure level of sensitive equipment caused by voltage sag. Proceedings of the CSEE, 2010. 30(10): p. 36-42.

[5] San Park, J. and T. Hyun Kim, Do types of organizational culture matter in nurse job satisfaction and turnover intention? Leadership in Health Services, 2009. 22(1): p. 20-38.

[6] Sellgren, S., G. Ekvall, and G. Tomson, Nursing staff turnover: does leadership matter? Leadership in Health Services, 2007. 20(3): p. 169-183.

[7] Bandhanpreet Kaur, M.a.D.P., Antecedents of Turnover Intentions. Global Journal of Management and Business Studies., 2013. 3: p. 1219-1230.

[8] Mencar, C., C. Castiello, and A.M. Fanelli. Interpretability assessment of fuzzy rule-based classifiers. in International Workshop on Fuzzy Logic and Applications. 2009. Springer.

[9] Asmamaw, T., Assessment of Knowledge, Attitude and Intension of Health Science Students Toward Safe Abortion Care Provision in Debre Markose University, Ethiopia. 2011, Addis Ababa University. 
[10] Jha, S., Determinants of Employee Turnover Intentions: A Review. Management Today, 2009. 9(2).

[11] Waldman, J.D., et al., The shocking cost of turnover in health care. Health care management review, 2004. 29(1): p. 2-7.

[12] Tett, R.P. and J.P. Meyer, Job satisfaction, organizational commitment, turnover intention, and turnover: path analyses based on meta-analytic findings. Personnel psychology, 1993. 46(2): p. 259-293.

[13] Ali Jadoo, S.A., et al., Job satisfaction and turnover intention among Iraqi doctors - a descriptive cross-sectional multicentre study. Hum Resour Health, 2015. 13: p. 21.

[14] Jadoo, S.A.A., et al., Job satisfaction and turnover intention among Iraqi doctors-a descriptive cross-sectional multicentre study. Human resources for health, 2015. 13(1): p. 21.

[15] Tsai, Y.H., et al., Work hours and turnover intention among hospital physicians in Taiwan: does income matter? BMC Health Serv Res, 2016. 16(1): p. 667.

[16] Gesesew, H.A., et al., Health workforce acquisition, retention and turnover in southwest Ethiopian health institutions. Ethiopian Journal of Health Sciences, 2016. 26(4): p. 331.

[17] Asegid, A., T. Belachew, and E. Yimam, Factors Influencing Job Satisfaction and Anticipated Turnover among Nurses in Sidama Zone Public Health Facilities, South Ethiopia. Nurs Res Pract, 2014. 2014: p. 909768.

[18] Endager, A., Y. Mezgebu, and G. Measho, Turnover Intention and Associated Factors Among Health Professionals in University of Gondar Referral Hospital, Northwest Ethiopia. International Journal of Economics \& Management Sciences, 2014. 03(01).

[19] Endale Woldegiorgis, A., Health Professionals' Intention to Leave from Public Health Facilities and Its Determinants in Gambella Region, Southwest Ethiopia. American Journal of Health Research, 2015. 3(6): p. 386.

[20] Abera, E., M. Yitayal, and M. Gebreslassie, Turnover Intention and Associated Factors Among Health Professionals in University of Gondar Referral Hospital, Northwest Ethiopia. Int J Econ Manag Sci, 2014. 3(196): p. 2. 
[21] Lorber, M. and B. Skela Savič, Job satisfaction of nurses and identifying factors of job satisfaction in Slovenian Hospitals. Croatian Medical Journal, 2012. 53(3): p. 263-270.

[22] Tzeng, H.-M., The influence of nurses' working motivation and job satisfaction on intention to quit: an empirical investigation in Taiwan. International journal of nursing studies, 2002. 39(8): p. 867-878.

[23] Bonenberger, M., et al., The effects of health worker motivation and job satisfaction on turnover intention in Ghana: a cross-sectional study. Human resources for health, 2014. 12(1): p. 43.

[24] Yang, H., et al., Validation of work pressure and associated factors influencing hospital nurse turnover: a cross-sectional investigation in Shaanxi Province, China. BMC Health Serv Res, 2017. 17(1): p. 112.

[25] Patience Edoho, S.-A., Job Satisfaction among Nurses in Public Hospitals in Calabar, Cross River State Nigeria. American Journal of Nursing Science, 2015. 4(4): p. 231.

[26] Marinucci, F., et al., Factors affecting job satisfaction and retention of medical laboratory professionals in seven countries of Sub-Saharan Africa. Human resources for health, 2013. 11(1): p. 38.

[27] Mekuria Mengistu, M., Factors Associated to Job Satisfaction Among Healthcare Workers at Public Hospitals of West Shoa Zone, Oromia Regional State, Ethiopia: A Cross Sectional Study. Science Journal of Public Health, 2015. 3(2): p. 161.

[28] Cortese, C.G., Predictors of critical care nurses' intention to leave the unit, the hospital, and the nursing profession. Open Journal of Nursing, 2012. 02(03): p. 311326.

[29] Lee, S.Y., et al., Influence of the nursing practice environment on job satisfaction and turnover intention. J Prev Med Public Health, 2014. 47(5): p. 258-65.

[30] Atnafu, K., G. Tiruneh, and T. Ejigu, Magnitude and associated factors of health professionals' attrition from public health sectors in Bahir Dar City, Ethiopia. Health, 2013. 05(11): p. 1909-1916.

[31] Asegid, A., T. Belachew, and E. Yimam, Factors Influencing Job Satisfaction and Anticipated Turnover among Nurses in Sidama Zone Public Health Facilities, South Ethiopia. Nursing Research and Practice, 2014. 2014: p. 909768. 
[32] Osuji, J., et al., Understanding the Factors That Determine Registered Nurses'

Turnover Intentions. Research and theory for nursing practice, 2014. 28(2): p. 140161.

[33] Tesfaye, M., Assessment on factors influencing the job satisfaction level of medical laboratory professionals working in Addis Ababa government hospitals. 2014, AAU.

[34] Ojakaa, D., S. Olango, and J. Jarvis, Factors affecting motivation and retention of primary health care workers in three disparate regions in Kenya. Human resources for health, 2014. 12(1): p. 33.

[35] Mobley, W.H., et al., Review and conceptual analysis of the employee turnover process. Psychological bulletin, 1979. 86(3): p. 493.

[36] Dachew, B.A., et al., High proportion of intention to leave among academic staffs of the University of Gondar, Northwest Ethiopia: a cross-sectional institution-based study. International Journal of Innovations in Medical Education and Research, 2016. 2(1): p. 23-27.

\section{Figures}

\section{Conceptual framework}

\section{Job Satisfaction dimension factors}

1. Performance appraisal

2. Autonomy

3. Professional develop't

4. Org's policy and strategy

5. Physical Work environment

6. Co-worker r/n ship

7. Supervisor support

8. Work load

9. Recognition and reward

10. Nature of work

11. Pay and benefit

\begin{tabular}{|l|l|}
\hline \multicolumn{1}{|c|}{$\begin{array}{c}\text { Intention } \\
\text { To leave }\end{array}$} \\
\hline ssociated facto & Socio-demographic and \\
\hline 1. Age & 2. Sex \\
3. & Marital status \\
4. Work experience \\
5. Working institutions \\
6. Educational level \\
7. Job Position \\
8. Family arrangement \\
9. Salary \\
\hline
\end{tabular}


Figure 1 : Conceptual framework of factors affecting HI's Turnover Intention

Source: Developed by reviewing different kinds of literature [21, 32, 33]

\section{Tables}

Table 1: socio-demographic characteristics of health information technology professionals working in south Gondar zone governmental health facility 2020, $(n=122)$

\begin{tabular}{|c|c|c|c|}
\hline Variable & Category & Frequency & Percentage \\
\hline \multirow[t]{2}{*}{ Age } & $20-29$ & 61 & 64.3 \\
\hline & $30-39$ & 34 & 35.8 \\
\hline \multirow[t]{2}{*}{ Sex } & Male & 46 & 48.4 \\
\hline & Female & 49 & 51.6 \\
\hline \multirow[t]{3}{*}{ Education level } & Diploma & 92 & 96.8 \\
\hline & Degree & 2 & 2.1 \\
\hline & MSC and Above & 1 & 1.1 \\
\hline \multirow[t]{6}{*}{ Working Institution } & Zonal Health Department & 6 & 6.3 \\
\hline & Health Center & 50 & 52.6 \\
\hline & Woreda Health Office & 14 & 14.7 \\
\hline & Hospital & 25 & 26.3 \\
\hline & $1-5$ & 65 & 68.4 \\
\hline & $6-10$ & 30 & 31.6 \\
\hline \multirow[t]{3}{*}{ Marital status } & Single & 50 & 52.6 \\
\hline & Married & 44 & 46.3 \\
\hline & Divorced & 1 & 1.1 \\
\hline \multirow[t]{3}{*}{ Current position } & Monitoring and Evaluation (M\&E) & 8 & 8.4 \\
\hline & HMIS officer & 66 & 69.5 \\
\hline & Data clerk & 21 & 22.1 \\
\hline \multirow{3}{*}{$\begin{array}{l}\text { Monthly salary } \\
\text { (Ethiopian Birr) }\end{array}$} & $<3145$ br & 3 & 3.2 \\
\hline & $3145-3911 \mathrm{br}$ & 42 & 44.4 \\
\hline & $3912-4725 \mathrm{br}$ & 46 & 48.4 \\
\hline
\end{tabular}




\begin{tabular}{|l|l|l|l|}
\hline & $>4725$ br & 4 & 4 \\
\hline Family Arrangement & Live with family & 37 & 38.9 \\
\cline { 2 - 4 } & Live far from family & 58 & 61.1 \\
\hline Respondents have Children < 18 & Yes & 21 & 22.1 \\
\cline { 2 - 4 } year & No & 74 & 77.9 \\
\hline $\begin{array}{l}\text { Respondents having alternative } \\
\text { job opportunities }\end{array}$ & Yes & 2 & 2.1 \\
\cline { 2 - 4 } & No & 93 & 97.9 \\
\hline
\end{tabular}

Table 2:- Level of job satisfaction by different dimensions among health information professionals in South Gondar zone public health facilities, Ethiopia, 2020 ( $n=122)$.

\begin{tabular}{|c|c|c|c|}
\hline Variable & Category & Number & percentage \\
\hline \multirow[b]{2}{*}{ Performance appraisal } & Satisfied & 48 & 39.3 \\
\hline & Dissatisfied & 74 & 60.7 \\
\hline \multirow[b]{2}{*}{ Autonomy } & Satisfied & 54 & 44.3 \\
\hline & Dissatisfied & 68 & 55.7 \\
\hline \multirow[b]{2}{*}{ Professional Development } & Satisfied & 19 & 15.6 \\
\hline & Dissatisfied & 103 & 84.4 \\
\hline \multirow[b]{2}{*}{ Co-worker relationship } & Satisfied & 114 & 93.4 \\
\hline & Dissatisfied & 8 & 6.6 \\
\hline \multirow[b]{2}{*}{ Benefits and pay } & Satisfied & 4 & 3.3 \\
\hline & Dissatisfied & 118 & 96.7 \\
\hline \multirow[b]{2}{*}{ Policy and strategy } & Satisfied & 90 & 73.8 \\
\hline & Dissatisfied & 32 & 26.2 \\
\hline \multirow[b]{2}{*}{ Working environment } & Satisfied & 66 & 54.1 \\
\hline & Dissatisfied & 56 & 45.9 \\
\hline \multirow[t]{2}{*}{ Supervisor support } & Satisfied & 84 & 68.9 \\
\hline & Dissatisfied & 38 & 31.1 \\
\hline \multirow[b]{2}{*}{ Workload } & Low & 40 & 32.8 \\
\hline & High & 82 & 67.2 \\
\hline Recognition & Satisfied & 67 & 54.9 \\
\hline
\end{tabular}


YalgawLibsuyeZimamu Page 30

Nature of the work

\begin{tabular}{|l|l|l|} 
Dissatisfied & 55 & 45.1 \\
\hline Satisfied & 61 & 50 \\
\hline Dissatisfied & 61 & 50 \\
\hline
\end{tabular}

Table 3:Factors associated with intention to leave among health information professionals in South Gondar zone public health facilities, Ethiopia, $2020(n=122)$.

\begin{tabular}{|c|c|c|c|c|}
\hline \multirow[t]{2}{*}{ Variables } & \multicolumn{2}{|c|}{ Intention to leave } & \multirow[t]{2}{*}{ COR $(95 \% \mathrm{CI})$} & \multirow[t]{2}{*}{$\operatorname{AOR}(95 \%, C I)$} \\
\hline & Yes & No & & \\
\hline $\begin{array}{l}\text { sex } \\
\text { Male } \\
\text { Female }\end{array}$ & $\begin{array}{l}28(23 \%) \\
51(41.8 \%)\end{array}$ & $\begin{array}{l}21(17.2 \%) \\
22(18 \%)\end{array}$ & $\begin{array}{l}\text { [OR: } 1.74(0.82-3.7)] \\
1\end{array}$ & -------------------- \\
\hline Marital status & & & & \\
\hline $\begin{array}{l}\text { Married } \\
\text { Single }\end{array}$ & $\begin{array}{l}32(26.23 \%)) \\
47(38.5 \%)\end{array}$ & $\begin{array}{l}25(20.5 \%) \\
18(14.8 \%)\end{array}$ & $\begin{array}{l}\text { [OR:0.49(0.231-1.042)] } \\
1\end{array}$ & $\begin{array}{l}*[\mathrm{OR}: 0 . \\
40349(.172-.948)] \\
1\end{array}$ \\
\hline Current positic & & & & \\
\hline $\begin{array}{l}\text { M\&E } \\
\text { HMIS officer } \\
\text { Data clerk }\end{array}$ & $\begin{array}{l}54(44.3 \%) \\
6(4.9 \%) \\
19(15.57 \%)\end{array}$ & $\begin{array}{l}36(29.5 \%) \\
3(2.5 \%) \\
4(3.3 \%)\end{array}$ & $\begin{array}{l}\text { [OR:0.421(0.073- } \\
1.042)] \\
\text { [OR:0.32(.099-1.005)] } \\
1\end{array}$ & ------ \\
\hline $\begin{array}{l}\text { Monthly salary } \\
<3145\end{array}$ & $2(1.64 \%)$ & $3(2.5 \%)$ & [OR: 3.7(.561-24.42)] & \\
\hline
\end{tabular}


YalgawLibsuyeZimamu Page 31

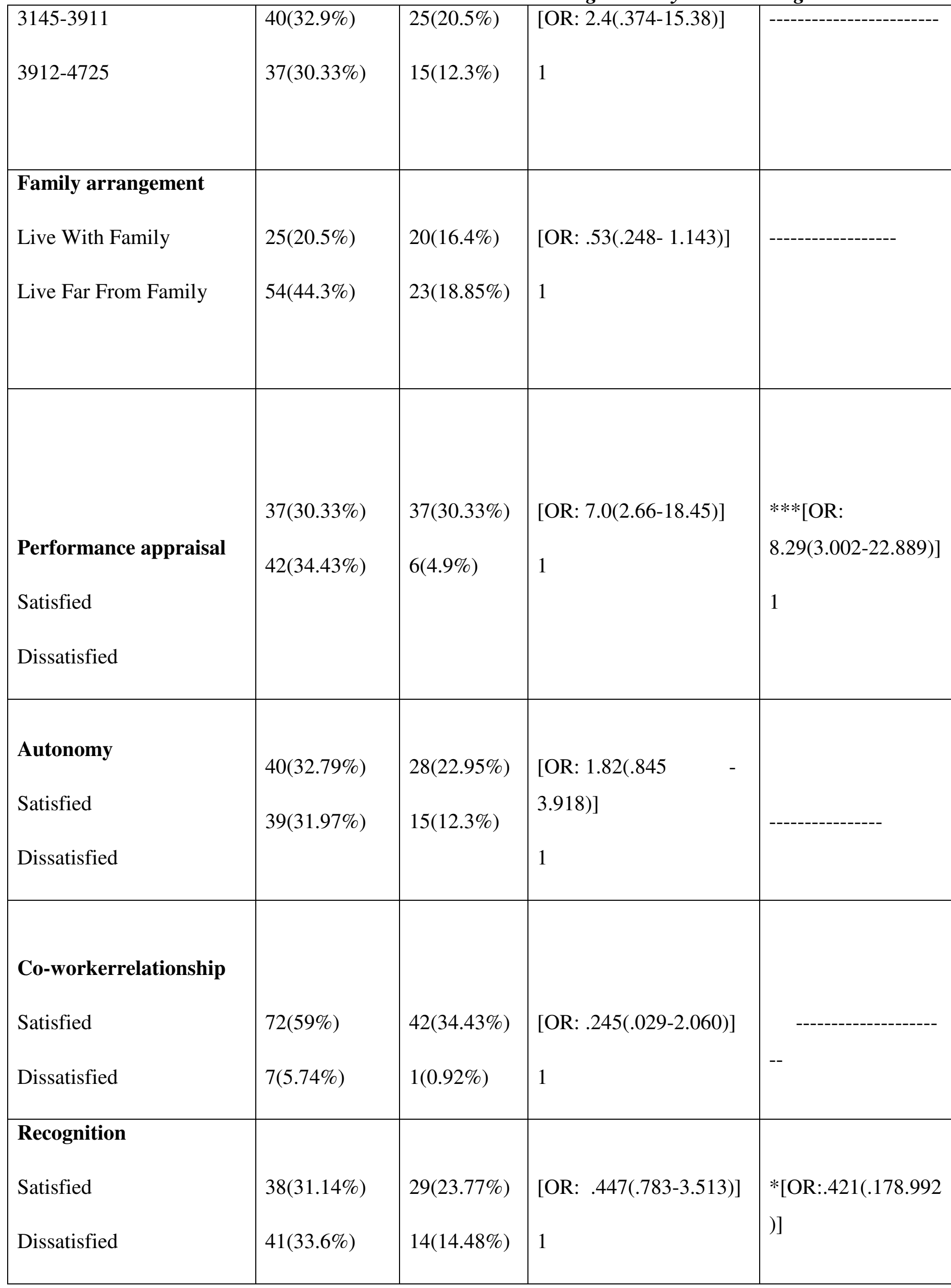




\begin{tabular}{|l|l|l|l|l|}
\hline & & & & 1 \\
\hline Nature of the work & & & & \\
Satisfied & $36(29.5 \%)$ & $25(20.49 \%)$ & [OR: 1.659(.206-.972)] & ------------- \\
Dissatisfied & $43(35.25 \%)$ & $18(14.75 \%)$ & 1 & \\
\hline
\end{tabular}

Notes: 1=reference group, *significant p-value $<0.05$, CI, confidence interval; COR, crude odds ratio; AOR, adjusted odds ratio. 